\title{
Synchronous fluorescence spectra of water contaminated by dispersed crude oil
}

\author{
EMILIA BASZANOWSKA*, ZBIGNIEW OTREMBA \\ Gdynia Maritime University, Physics Department, Morska 81-87, 81-226 Gdynia, Poland \\ ${ }^{*}$ Corresponding author: e.baszanowska@wm.umg.edu.pl
}

\begin{abstract}
The development of petroleum extraction and transport technology does not ensure complete isolation of these substances from the natural environment. This problem is exacerbated by the location of mining equipment on the sea shelf and the fact that numerous submarine pipelines, tankers and handling terminals can also emit oil pollution. Therefore, the possibility of detecting oil dispersed in the water is particularly important. This paper reports the efforts to identify methods of characterization of the water containing the crude oil emulsion in a very low concentration (a few to several tens of $\mathrm{ppm}$ ). Due to this, the effect of emulsion concentration on the possibility of its objective characterization using synchronous fluorescence spectra was studied. The similarity of spectra at various oil concentrations was analysed. It has been shown that the stabilization of the shape of synchronous fluorescence spectra occurs at relatively low oil concentrations.
\end{abstract}

Keywords: petroleum, dispersed oil, synchronous fluorescence spectroscopy, marine environment.

\section{Introduction}

Highly-developed technologies of oil extraction and its transport do not ensure complete isolation of these substances from the natural environment. The daily oil production is nearly 13 million cubic meters ( 84 million barrels per day) [1]]. About 5.5 million cubic tonnes of oil is transported daily on sea routes [2] . A small fraction of this quantity has a chance to find itself in sea water. However, also taking into account various types of crude oil residues and products of its processing (i.e., fuels, lubricants), which are also transported by ships and constitute ship consumables, a significant amount of oils unintentionally get into the surface waters. Catastrophic oil spills are documented in a sufficiently quantitative way [ $\underline{3}-\underline{5}]$. However, it is difficult to determine the frequency of sea pollution incidents resulting from the normal operation of mining equipment, the operation of ship power plants, pipeline connections or transshipment installations.

Oil found in the marine environment appears on the sea surface as an oil film and is subjected to the action of waves as well as wind and sunshine. Over time, oil exposed to natural factors partially evaporates and a small percentage of the oil may dissolve and disperse in the seawater as an oil-in-water emulsion. 
Oil substances spreading on the surface of the water are visible from the air or even from the space [ $[$ ] and are able to be detected by optical or radar methods [7]. It is known, however, that oil contaminants can also be found below the sea surface-especially under strong wavelength conditions and mostly when dispersants are used when combating spillage.

Taking into account the protection of the natural marine ecosystem, it is a challenge to expand the knowledge of oil pollutants and find an efficient oil detection method for the smallest oil amount in seawater in both coastal and open waters.

Petroleum and its products consist of a mixture of mono- and polycyclic hydrocarbons which contain fluorophoric centres. Laboratories use a variety of methods to study the complex structure of petroleum products. However, the presence of fluorophoric centres in oil structures allows oil to be studied using fluorescence methods. The spectrum of light emitting by fluorophores is modified by other processes, mainly absorption by various compounds or even repeated fluorescence [ $\underline{8}]$. Therefore, fluorescence must be accompanied by other methods such as absorption spectroscopy in ultraviolet (UV), visible (VIS) range and sometimes even infrared (IR) [9-12]. The high sensitivity of fluorescence spectroscopy is the key to applying the method as a powerful tool to study the complex structure of petroleum products both in laboratory and in situ conditions. Fluorescence spectroscopy allows measurements to be performed in different methods used in stationary methods, such as fluorescence spectroscopy for single excitation wavelength (SWEx) or single emission wavelength (SWEm), excitation-emission spectroscopy (EEMs) [13-15] and synchronous fluorescence spectroscopy (SFS) [16, 17] which was described by Lloyd [18] (and was used to study petroleum products [19], including directly in the marine environment [20]). The challenge for scientists is the possibility to monitor the spectroscopic transformations of petroleum products while in contact with the environment. In this field there have been attempts to use time-resolved fluorescence spectroscopy [21, 22].

In order to determine the presence of oil under the surface of the water, a sample of water for chemical analysis must be taken. However, the best way would be to use a sensor dedicated to detecting dispersed oil. Therefore, we have undertaken research into the fluorescence of water in oil contamination. Pure sea water also fluoresces, and this is due to dissolved substances that naturally occur in the sea. Therefore, distinguishing the fluorescence of natural marine constituents from the fluorescence derived from impurities is a matter of the way in which the analyses described in this article are included. We are seeking a solution that is relatively simple, yet contains significant spectral information. The point is not to make unjustifiably wide measurements, i.e., in the spectral range in which the fluorescence of natural water components such as coloured dissolved organic matter (CDOM) or fluorescent dissolved organic matter (FDOM) or pigments [ $\underline{23}-27]$ which display their own fluorescence spectra and partly overlap with the fluorescence of the oil.

In this work, we present the characteristics of crude oil in a dispersed form, using so-called synchronous spectra, i.e., fluorescence as a function of the excitation wavelength, but with a permanent difference between the excitation wavelength and the emis- 
sion wavelength. This type of spectrofluorometry has been known for decades [18], as well as in relation to liquid hydrocarbons [19]. Analyses of hexane solutions of oils in terms of the shapes of synchronous spectra have already been carried out [2ㅇ, 29]. However, in this article we present fluorometric characterization directly of water contaminated with dispersed oil.

\section{Method}

\subsection{Samples preparation}

As an oil sample, crude oil extracted from seabed in Polish Exclusive Economic Zone (the southern part of the Baltic Sea) and aired for one hour in a fume hood at room temperature was chosen to prepare the oil samples. The oil density used in the tests was $8.75 \mathrm{~g} / \mathrm{cm}^{3}$ at $20^{\circ} \mathrm{C}$.

Dispersed in demineralized water $\left(1 \mathrm{dm}^{3}\right)$, the oil sample $\left(10 \mathrm{~cm}^{3}\right)$ was prepared using a high-speed stirrer (Steinberg SMS-ER-3000, $3000 \mathrm{rpm}, 1$ hour). Next, the oil-in-water emulsion was stored in the dark at $20^{\circ} \mathrm{C}$ for one week in order to stabilize the oil-in -water system. Finally, four individual concentrations of oil-in-water emulsion samples ranging from 5.59 to $55.4 \mathrm{ppm}$ were prepared [30]. The concentration of crude oil was determined by measuring the fluorescence intensity (excitation $210 \mathrm{~nm}$, emission $295 \mathrm{~nm}$ ) of oil extracted from studied samples to $n$-hexane, in relation to the standard solutions previously prepared.

\subsection{Measurements}

Using Aqualog Horiba spectrofluorometer, measurements of excitation-emission spectra in $1 \times 1 \mathrm{~cm}$ quartz cuvette were performed [30]. The fluorimeter consists of a polychromator and a CCD camera. The high level energy gain setup was applied to the CCD camera. For measurements, the following parameters were applied: excitation wavelength from 240 to $600 \mathrm{~nm}$ with a $5 \mathrm{~nm}$ sampling interval, emission wavelength from 212.75 to $622.97 \mathrm{~nm}$ with a $1.623 \mathrm{~nm}$ sampling interval, $5 \mathrm{~nm}$ excitation slit, $5 \mathrm{~nm}$ emission slit and $1 \mathrm{~s}$ integration time.

\section{Results and discussion}

The total synchronous fluorescence (TSF) spectra for dispersed crude oil in water were determined based on measured excitation-emission spectra [이 ] using the wavelength interval $\Delta \lambda$ - the so-called offset $[\underline{16}, \underline{18}]$ :

$$
\Delta \lambda=\lambda_{\mathrm{em}}-\lambda_{\mathrm{ex}}
$$

where $\Delta \lambda$ is the wavelength interval (offset), $\lambda_{\mathrm{ex}}-$ the excitation wavelength, and $\lambda_{\mathrm{em}}-$ the emission wavelength.

Figure 1 presents the TSF spectra for considered concentrations of oil. The most important information about the position of maximum fluorescence in this $3 \mathrm{D}$ spectrum is 

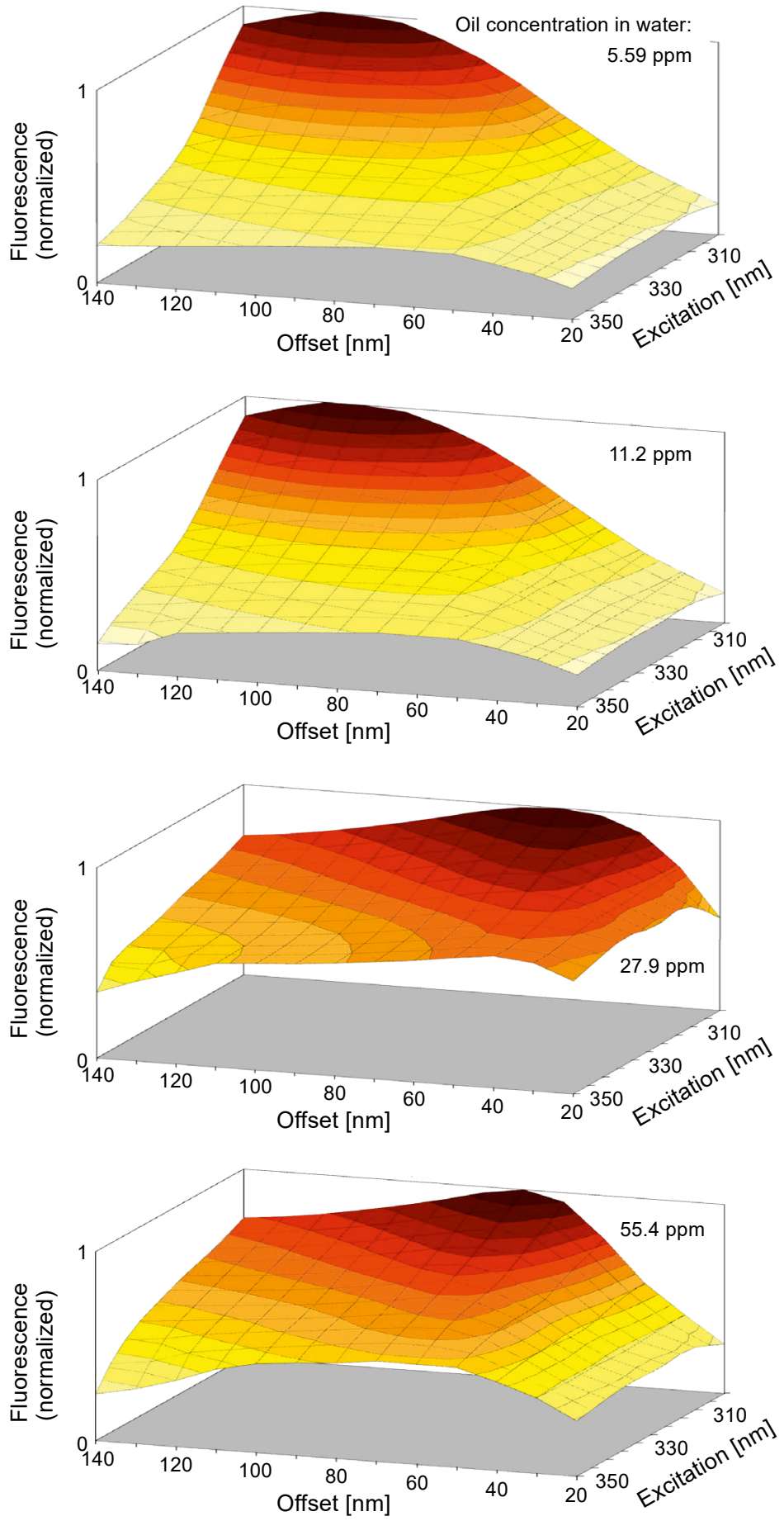

Fig. 1. Total synchronous spectra for various oil concentrations as a function of two variables: excitation wavelength and offset value. 
fixed in the specific point - the wavelength-interval fluorescence maximum $\left(\operatorname{Ex}_{\max } / \Delta \lambda\right)$ described by the excitation wavelength $\operatorname{Ex}_{\max }$ corresponding to the offset $\Delta \lambda$ [29]] Therefore, the TSF spectra were normalized.

Figure 1 shows that the fluorescence peak position depends on the oil concentration. The peak for low concentrations $(5.59$ and $11.2 \mathrm{~nm}$ ) was detected for the excitation wavelength $300 \mathrm{~nm}$ which corresponds to a wavelength-interval of about 100-130 nm with the fluorescence maximum at $120 \mathrm{~nm}\left(\mathrm{Ex}_{\max }=300 / \Delta \lambda=120\right)$. On the other hand, for higher oil concentrations the peak was detected for excitation wavelength $300 \mathrm{~nm}$, which corresponds to a wavelength-interval of about $60-80 \mathrm{~nm}$ with the fluorescence maximum at $70 \mathrm{~nm}\left(\mathrm{Ex}_{\max }=300 / \Delta \lambda=70\right)$. Taking into account the above-mentioned fact, in Fig. 1 a shift in the position of the fluorescence maximum to the lower offsets is observed with an increase in crude oil concentration. However, for low oil concentrations (5.59 and $11.2 \mathrm{ppm}$ ) the maximum fluorescence was stabilized. This is a key fact for the possibility of detecting dispersed oil in water for low oil concentrations.

The effect of moving the fluorescence maximum towards the lower values of the offset observed with increasing concentration may be caused by a decrease in the number of photons reaching the fluorescing molecules. As a result, the spectrum of fluorescence changes, its intensity decreases and the wavelength at which the maximum occurs varies $[\underline{31}, \underline{32}]$.

The three-dimensional plot allows fluorescence to be shown only from the excitation wavelength at $300 \mathrm{~nm}$, while the fluorescence has already been measured from $240 \mathrm{~nm}$. Illustrating the dependence of fluorescence in the entire excitation wavelength range requires the preparation of two-dimensional graphs. To obtain the specified information about fluorescence dependence on the excitation wavelength and offset, the synchronous fluorescence spectrum for a single offset $\Delta \lambda$ for considered dispersed crude oil concentration was determined. Figure 2 presents the changes in synchronous spectra for various offsets for particular oil concentrations. It is visible that both from $\Delta \lambda=40 \mathrm{~nm}$ and $\Delta \lambda=60 \mathrm{~nm}$, variations of the shape of synchronous spectra with oil concentration are the biggest. For $\Delta \lambda=40 \mathrm{~nm}$ the independence from the oil concentration is observed for a lower oil concentration from 5.59 to $11.2 \mathrm{ppm}$ (fluorescence maximum is observed for $265 \mathrm{~nm}$ ) and for the higher oil concentration in the shape of synchronous spectra, only small changes were observed (fluorescence maximum changes from 260 to $255 \mathrm{~nm}$ ).

In order to assess the degree of similarity of synchronous spectra, when the concentration of oil dispersed in water is changing, the value of the similarity parameter was calculated as

$$
S_{x-y}=1-\frac{\sum_{i j}\left|x_{i j}-y_{i j}\right|}{\sum_{i j} x_{i j}+\sum_{i j} y_{i j}}
$$

where: $S_{x-y}$ - similarity parameter between matrix $x$ and matrix $y$, and $x_{i j}, y_{i j}$ - elements of matrices. The calculated similarity takes values from 0 (total lack of similarity) to 1 (identity). 

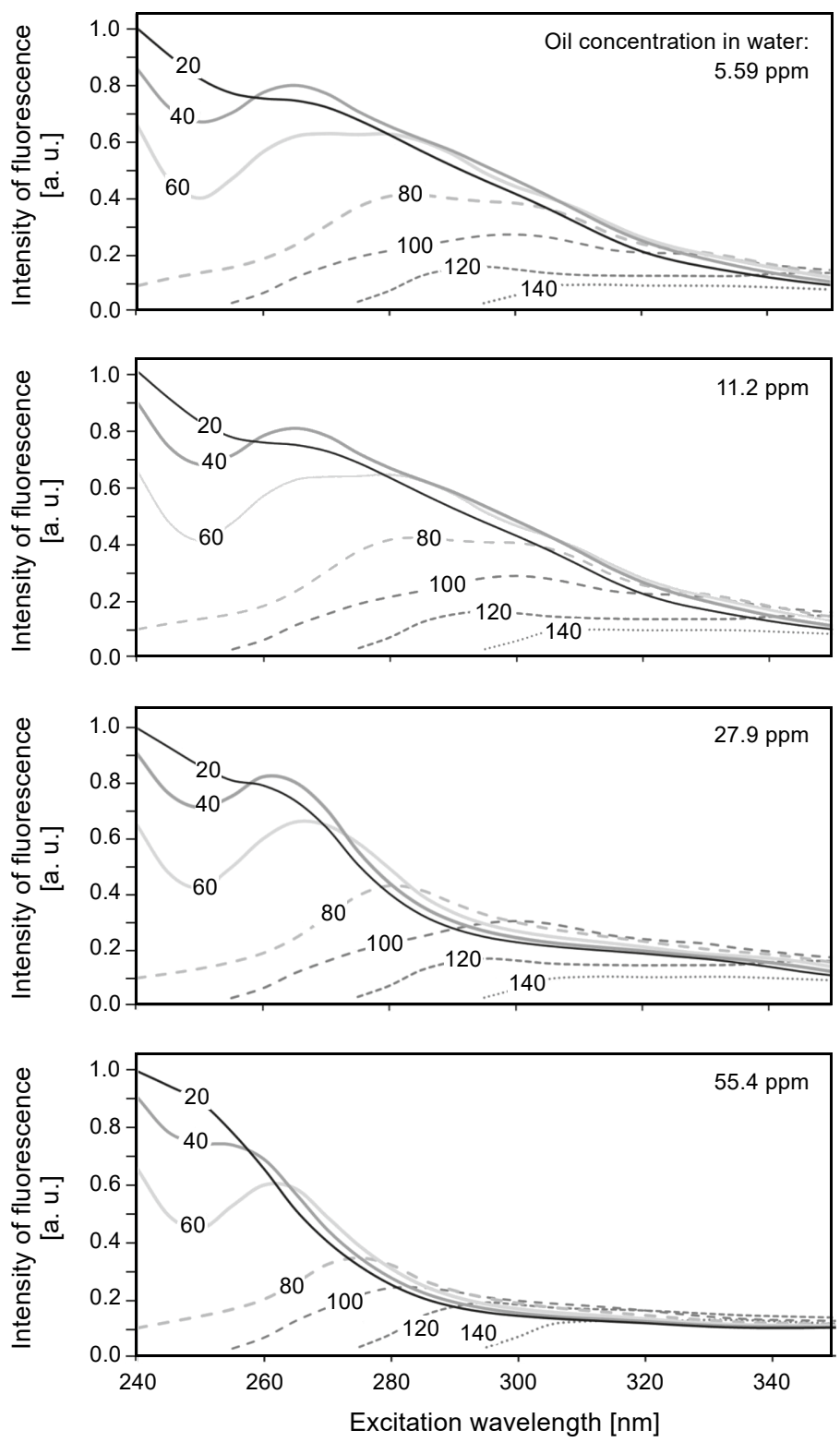

Fig. 2. Synchronous fluorescence spectra for different oil concentrations at various values of offset.

Comparisons of spectral shapes for four concentrations of oil in water were performed. Spectra were compared on a peer-to-peer basis, and graphical results are shown in Fig. 3. Taking into account the similarity parameter in relation to the increasing oil concentration, it was observed that the similarity parameter decreases when the oil concentration increases. In the range of samples with concentrations from 5.59 to $55.4 \mathrm{ppm}$, the similarity parameter changes within the limits of $0.77-0.97$. At the current stage of 


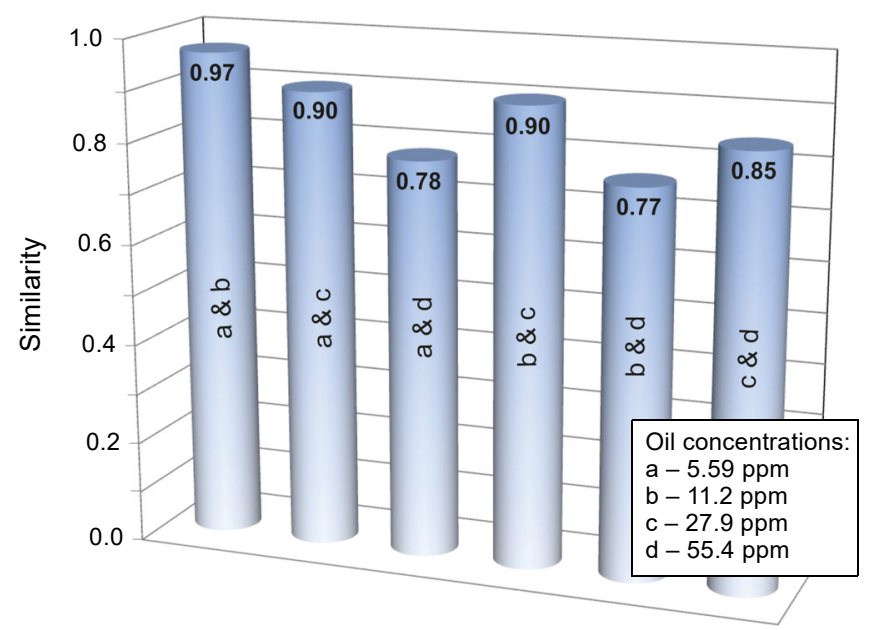

Fig. 3. The value of similarity determined in pairs for different oil concentrations.

analysis, it is not possible to assess whether these similarities are large enough to use the shapes of synchronous spectra to identify the type of oil that penetrates into the water environment in a dispersed form.

\section{Conclusions}

Synchronous fluorescence of water contaminated with dispersed oil provides spectral information that reflects the presence of such contaminants in water when the analysis is performed directly in the water in the UV. The most dynamic synchronous spectrum and, therefore, the most representative for water with the addition of crude oil emulsion, was obtained for $40 \mathrm{~nm}$ offset.

At the current stage of research presented in this paper, it appears that the method of synchronous spectra may be useful in designing a detector for oil dispersed in water. The presented example applies to crude oil, while other types of oils, especially the products of petroleum processing, should also manifest themselves in the water column in the form of a characteristic synchronous spectrum.

Acknowledgements - This work was supported by Gdynia Maritime University grant No. WM/2020/PZ/05.

\section{References}

[1] Ycharts, World Crude Oil Production, 2018. https://ycharts.com/indicators/world_crude_oil_production (accessed February 25, 2019).

[2] Statista, Transport volume of crude oil in global seaborne trade from 2010 to 2017, 2017. https:// www.statista.com/statistics/264013/transport-volume-of-crude-oil-in-seaborne-trade/ (accessed June 2019).

[3] Ji Z.-G, Johnson W., Wikel G., Catastrophic oil spill analysis, Risk Analysis XI, WIT Transactions on Information and Communication Technologies, Vol. 47, 2014, pp. 17-25, DOI: 10.2495/RISK140021. 
[4] Michel J., Fingas M., Oil spills: causes, consequences, prevention, and countermeasures, [In] Fossil Fuels, [Ed.] G.M. Crawley, World Scientific, 2016, pp. 159-201, DOI: 10.1142/9789814699983 0007.

[5] HELCOM Indicators, Results and confidence volume of oil detected in the Baltic Sea, http:// www.helcom.fi/baltic-sea-trends/indicators/operational-oil-spills-from-ships/results-and-confidence (accessed June 2019).

[6] Hu C., Feng L., Holmes J., Swayze G.A., Leifer I., Melton C., Garcia O., MacDonald I., Hess M., Muller-Karger F., Graettinger G., Green R., Remote sensing estimation of surface oil volume during the 2010 Deepwater Horizon oil blowout in the Gulf of Mexico: scaling up AVIRIS observations with MODIS measurements, Journal of Applied Remote Sensing 12(2), 2018, article 026008, DOI: $10.1117 / 1 . J R S .12 .026008$.

[7] Fingas M., Oil Spill Science and Technology, 2nd Ed., Elsevier, 2017.

[8] Lakowicz J.R., Principles of Fluorescence Spectroscopy, 3rd Ed., Springer, Boston, MA, 2006, DOI: 10.1007/978-0-387-46312-4.

[9] Downare T.D., Mullinst O.C., Visible and near-infrared fluorescence of crude oils, Applied Spectroscopy 49(6), 1995, pp. 754-764, DOI: 10.1366/0003702953964462.

[10] Wang Z., Stout S.A., Oil Spill Environmental Forensics: Fingerprinting and Source Identification, Elsevier, 2007.

[11] SKou N., Sorensen B., Poulson A., A new airborne dual frequency microwave radiometer for mapping and quantifying mineral oil on the sea surface, Proceedings of the Second Thematic Conference on Remote Sensing for Marine and Coastal Environments, ERIM Conferences, 1994, Ann Arbor, Michigan, pp. II559-II565.

[12] Zielinski O., Busch J.A., Cembella A.D., Daly K.L., Engelbrektsson J., Hannides A.K., Schmidt H., Detecting marine hazardous substances and organisms: sensors for pollutants, toxins and pathogens, Ocean Science 5(3), 2009, pp. 329-349, DOI: 10.5194/os-5-329-2009.

[13] Baszanowska E., Zielinski O., Otremba Z., ToczeK H., Influence of oil-in-water emulsions on fluorescence properties as observed by excitation-emission spectra, Journal of the European Optical Society - Rapid Publications 8, 2013, article 13069, DOI: 10.2971/jeos.2013.13069.

[14] Baszanowska E., Otremba Z., Spectral signatures of fluorescence and light absorption to identify crude oils fund in the marine environment, Journal of the European Optical Society - Rapid Publications 9, 2014, article 14029, DOI: 10.2971/jeos.2014.14029.

[15] Baszanowska E., Otremba Z., Fluorometry in application to fingerprint of petroleum products present in the natural waters, Journal of the European Optical Society-Rapid Publications 12, 2016, article 16, DOI: $10.1186 / \mathrm{s} 41476-016-0018-4$.

[16] PAtra D., Mishra A., Total synchronous fluorescence scan spectra of petroleum products, Analytical and Bioanalytical Chemistry 373(4-5), 2002, pp. 304-309, DOI: 10.1007/s00216-002-1330-y.

[17] Poryvkina L., Babichenko S., Davydova O., SFS characterisation of oil pollution in natural water, Proceedings of Fifth International Conference on Remote Sensing for Marine and Coastal Environments, San Diego, California, October 5-7, 1998, Vol. 2, pp. 520-524.

[18] Lloyd J.B.F., Synchronized excitation of fluorescence emission spectra, Nature Physical Science 231, 1971, pp. 64-65, DOI: 10.1038/physci231064a0.

[19] Patra D., Mishra A.K., Recent developments in multi-component synchronous fluorescence scan analysis, Trends in Analytical Chemistry 21(12), 2002, pp. 787-798, DOI: $\underline{10.1016 / \mathrm{S} 0165-9936(02)}$ 01201-3.

[20] Shaver M., McGown L.B., Fluorescence studies of complex coal liquid samples using the lifetime synchronous spectrum (LiSS), Applied Spectroscopy 49(6), 1995, pp. 813-818, DOI: 10.1366/00037 02953964561.

[21] Baszanowska E., Otremba Z., Rohde P., Zielinski O., Adoption of the time resolved fluorescence to oil type identification, Journal of KONES Powertrain and Transport 18(2), 2011, pp. 25-29.

[22] Rohde P., Busch J.A., Henkel R.H., Voss D., Zielinski O., Detection and identification of hydrocarbons in marine waters using time-resolved laser-fluorescence: set-up and first results of a new 
submersible sensor, Proceedings OCEANS 2009-EUROPE, Bremen, Germany 2009, pp. 1-5, DOI: 10.1109/OCEANSE.2009.5278101.

[23] Coble P.G., Colored dissolved organic matter in seawater, [In] Subsea Optics and Imaging. [Eds.] J. Watson, O. Zielinski, 1st Ed., Woodhead Publishing, 2013, pp. 98-119.

[24] Drozdowska V., Freda W., Baszanowska E., Rudź K., Darecki M., Heldt J., Toczek H., Spectral properties of natural and oil polluted Baltic seawater - results of measurements and modelling, The European Physical Journal Special Topics 222(9), 2013, pp. 2157-2170, DOI: 10.1140/epjst/ e2013-01992-x.

[25] Kowalczuk P., Stoń-Egiert J., Cooper W.J., Whitehead R.F., Durako M.J., Characterization of chromophoric dissolved organic matter (CDOM) in the Baltic Sea by excitation emission matrix fluorescence spectroscopy, Marine Chemistry 96(3-4), 2005, pp. 273-292, DOI: 10.1016/j.marchem. 2005.03.002.

[26] Miranda M., Trojzuck A., Voss D., Gassmann S., Zielinski O., Spectroscopic evidence of anthropogenic compounds extraction from polymers by fluorescent dissolved organic matter in natural water, Journal of the European Optical Society-Rapid Publications 11, 2016, article 16014, DOI: 10.2971/jeos.2016.16014.

[27] Zielinski O., RÜssmeier N., Ferdinand O.D., Miranda M.L., Wollschläger J., Assessing fluorescent organic matter in natural waters: towards in situ excitation-emission matrix spectroscopy, Applied Sciences 8(12), 2018, article 2685, DOI: 10.3390/app8122685.

[28] Baszanowska E., Otremba Z., Oil identification based on total synchronous spectra, Journal of KONES Powertrain and Transport 21(2), 2014, pp. 15-20, DOI: 10.5604/12314005.1133857.

[29] Baszanowska E., OtRemba Z., Description of diesel fuel based on synchronous fluorescence spectroscopy, Journal of KONES Powertrain and Transport 24(1), 2017, pp. 39-45, DOI: $10.5604 /$ $\underline{01.3001 .0010 .2793 .}$

[30] Baszanowska E,. Otremba Z., Properties of the Baltic crude oil in the oil-in-water emulsion form: excitation-emission spectra, Journal of KONES Powertrain and Transport 25(1), 2018, pp. 7-14, DOI: $10.5604 / 01.3001 .0012 .2438$.

[31] Ralston C.Y., Wu X., Muluins O.C., Quantum yields of crude oils, Applied Spectroscopy 50(12), 1996, pp. 1563-1568, DOI: 10.1366/0003702963904601.

[32] Steffens J., Landulfo E., Courrol L.C., Guardani R., Application of fluorescence to the study of crude petroleum, Journal of Fluorescence 21, 2011, pp. 859-864, DOI: 10.1007/s10895-009-0586-4. 